\title{
LA DOCTRINA DE LA DRITTWIRKUNG DER GRUNDRECHTE EN LA JURISPRUDENCIA DE LA CORTE INTERAMERICANA DE DERECHOS HUMANOS
}

\author{
JAVIER MIJANGOS Y GONZÁLEZ \\ Profesor de Derecho Constitucional \\ Universidad Carlos III de Madrid
}

\section{SUMARIO}

I. Introducción.

II. El deber de respeto y vigilancia de los derechos fundamentales: la asunción de la state action.

III. La primera aproximación a la Drittwirkung: los derechos fundamentales como obligaciones erga omnes.

IV. La eficacia directa de los derechos fundamentales de la Convención Americana: la Opinión Consultiva 18/03.

\section{INTRODUCCIÓN}

En 1970 aparecía en la Revista Jurídica Veracruzana un artículo de Héctor Fix-Zamudio titulado "Algunos aspectos de la protección de los derechos humanos en las relaciones entre particulares en México y Latinoamérica ${ }^{1}$. FixZamudio, como en otras muchas cuestiones, fue uno de los primeros juristas latinoamericanos en plantear la posible vigencia de los derechos fundamentales en las relaciones entre particulares.

1 Dicho trabajo, a su vez, fue elaborado para el libro de homenaje en honor de René Cassín, y apareció en francés en el volumen III del Liber Amicorum Discipulorumque René Bassin. 
Dicho trabajo se escribió en una época en la que el tema en cuestión se encontraba en primera línea de discusión en la doctrina y jurisprudencia comparada. Así, mientras que en los Estados Unidos la doctrina de la state action del Tribunal Supremo alcanzaba su mayor fuerza expansiva, del otro lado del Atlántico el Tribunal Constitucional Federal alemán consolidaba la doctrina iniciada en el caso Lüth de 1958 y la dogmática alemana de la Drittwirkung der Grundrechte se convertía en un referente para el resto de la Europa continental ${ }^{2}$. En esos mismos años es posible constatar que diversos ordenamientos latinoamericanos — como fueron los casos de Argentina, Brasil, Bolivia, Chile, El Salvador, Guatemala, Nicaragua, Paraguay o Uruguayregularon diversos aspectos del juicio de amparo, o instrumentos similares, a fin de extender el ámbito protector del mismo a ciertas violaciones de derechos fundamentales cuyo origen se encontraba en las relaciones entre particulares ${ }^{3}$.

La discusión sobre la eficacia de los derechos fundamentales en las relaciones privadas ha corrido distinta suerte en ambos continentes. En el caso europeo, la mayoría de tribunales constitucionales han desarrollado una sólida doctrina en esta materia. En Latinoamérica, y salvando la riquísima doctrina elaborada por la Corte Constitucional colombiana ${ }^{4}$, la jurisprudencia de las respectivas cortes o tribunales constitucionales sobre la Drittwirkung se encuentra en una fase de desarrollo muy elemental o es prácticamente inexistente.

Uno de los varios motivos que provocan la pobreza jurisprudencial en esta materia en los ordenamientos jurídicos latinoamericanos, es el desconocimiento y rechazo a un referente común que no puede ser eludido por los tribunales nacionales en su quehacer diario. Me refiero a la jurisprudencia de la Corte Interamericana de Derechos Humanos. El presente trabajo tiene como objetivo dar cuenta de este cuerpo jurisprudencial, tan rico como poco estudiado, y que constituye una fuente de inapreciable valor para cualquier estudio que pretenda abordar de forma completa la vigencia de los derechos fundamentales en las relaciones privadas en los ordenamientos jurídicos latinoamericanos 5 .

2 A lo largo de estas páginas me permitiré utilizar el término alemán Drittwirkung, en virtud de que es la denominación otorgada a la problemática que nos ocupa en la dogmática alemana, origen de la hoy extensa bibliografía en materia de incidencia de los derechos fundamentales en las relaciones entre particulares. Esta razón se aúna al hecho de que el discurso académico en lengua castellana ha recogido y aceptado, con suficiente generalidad, dicha terminología.

3 Véase al respecto, H. Fix-Zamudio, "La protección jurídica y procesal frente a los grupos de presión", en Protección jurídica de los derechos humanos. Estudios comparativos, Comisión Nacional de Derechos Humanos, México, 1999 (1. ${ }^{\text {a }}$ ed. 1991), pp. 163-165.

4 Para una primera aproximación al caso colombiano véase a E. Cifuentes Muñoz, La eficacia de los derechos fundamentales frente a particulares, Universidad Nacional Autónoma de México, México, 1998; y A. Julio Estrada, La eficacia de los derechos fundamentales entre particulares, Universidad Externado de Colombia, Bogotá, 2000.

5 En virtud de los límites y objetivos de este trabajo, no me ocuparé de dos problemas previos que deben ser resueltos respecto a la aplicación del sistema interamericano de derechos hu- 
Si un lector desprevenido diese cuenta de aquellas obras que examinan los criterios jurisprudenciales de la Corte Interamericana de Derechos Humanos — en adelante CIDH - llegaría a la conclusión de que la Drittwirkung es una cuestión de escasa entidad en la jurisprudencia interamericana y que, en cualquier caso, no ha sido abordada de forma exhaustiva ni sistemática. Sin embargo, la realidad es muy distinta, ya que una vez estudiada la jurisprudencia regional de los últimos veinte años no resulta desventurado afirmar que la CIDH ha construido toda una teoría sobre la vigencia de los derechos fundamentales en las relaciones entre particulares en el ámbito latinoamericano. Estructuraremos nuestro análisis a través de tres etapas, sucesivas en el tiempo, y claramente identificables en la jurisprudencia.

La primera etapa se conforma por una serie de sentencias cuyo común denominador es el análisis de la obligación de respeto y vigilancia de los derechos fundamentales por parte de los Estados prevista en el artículo 1.1 de la Convención Americana de Derechos Humanos —en adelante CADH- Este principio, cuyo estudio es una constante en toda la jurisprudencia, llevará a la Corte Interamericana a planteamientos muy cercanos a los propuestos por la doctrina estadounidense de la state action.

En una segunda fase, la relevancia en la determinación de las características del agente que ha cometido la violación de los derechos fundamentales será sustituida por una serie de planteamientos en los que el carácter de la norma violada se convierte en el centro de atención. Es en este momento cuando la Corte Interamericana consagra la idea de que los derechos fundamentales previstos en la Convención resultan obligaciones erga omnes, que se imponen no sólo en relación con el poder del Estado sino también respecto a actuaciones de terceros particulares.

Por último, la tercera fase en la evolución de la jurisprudencia está representada por el caso más relevante en esta materia: la Opinión Consultiva 18/03 solicitada por los Estados Unidos Mexicanos sobre la condición jurídica de los inmigrantes. Esta resolución, que marca una tendencia hasta nuestros días, establece definitivamente la eficacia directa de los derechos fundamentales en las relaciones entre particulares.

Antes de dar inicio al análisis de la cuestión, quisiera dedicar este trabajo, como un humilde homenaje, al maestro Héctor Fix-Zamudio en sus 50 años de trabajo como investigador, uno de los mayores impulsores del sistema in-

manos en los ordenamientos internos. En primer término, la ampliación del catálogo de derechos humanos de los ordenamientos nacionales a través de la Convención Americana de Derechos Humanos y, en segundo lugar, la recepción de la jurisprudencia interamericana por parte de los órganos judiciales internos. Respecto al análisis de estas cuestiones véase J. Mijangos y González, Los derechos fundamentales en las relaciones entre particulares. Análisis del caso mexicano, Porrúa, México, 2007; así como F. Silva García, La eficacia interna de las sentencias del Tribunal Europeo $y$ de la Corte Interamericana de Derechos Humanos, tesis doctoral inédita, Universidad Carlos III de Madrid, 2006. Este trabajo representa el primer estudio, en la doctrina latinoamericana, que aborda de forma compleja las repercusiones que en el ámbito normativo de los Estados presentan las sentencias regionales estimatorias. Su próxima publicación será un referente en esta materia. 
teramericano de derechos humanos, y cuya obra ha marcado una escuela en el estudio de los derechos fundamentales y los sistemas comparados en la doctrina latinoamericana.

\section{EL DEBER DE RESPETO Y VIGILANCIA DE LOS DERECHOS FUNDAMENTALES: LA ASUNCIÓN DE LA STATE ACTION}

El caso Velásquez Rodríguez contra Honduras (1987) no sólo fue el primer asunto en el que la CIDH se planteó la cuestión de la eficacia de los derechos fundamentales en las relaciones privadas, sino que, al constituir el primer caso contencioso sometido a su competencia, es el documento que consagra los fundamentos de todo el sistema interamericano de derechos humanos. Este asunto, al igual que el caso Godinez Cruz contra Honduras (1987), Paniagua Morales contra Guatemala (1998), Bámaca Velásquez contra Guatemala (2000) y Juan Humberto Sánchez contra Honduras (2003), se enmarca dentro de la guerra sucia acaecida en Centroamérica durante la década de los ochenta, en la cual, aquellos individuos considerados como subversivos por el régimen en turno eran objeto de desapariciones forzadas y ejecuciones extrajudiciales.

En el estudio de esta primera fase nos centraremos en el caso Velásquez Rodríguez. Manfredo Velásquez, estudiante universitario relacionado con grupos subversivos, fue apresado de forma violenta y sin mediar orden judicial de captura por elementos de la policía secreta hondureña y por civiles que actuaban bajo su dirección. Al igual que en más de un centenar de casos sucedidos en Honduras entre 1981 y 1984, el señor Velásquez fue asesinado, después de haber sufrido diversas torturas, y enterrado en un cementerio clandestino.

La Comisión Interamericana sometió el caso a la competencia de la Corte con la finalidad de que ésta determinara si hubo violación, por parte de Honduras, de los artículos 4 (derecho a la vida), 5 (derecho a la integridad personal), y 7 (derecho a la libertad personal) de la CADH. Para la Corte, el análisis, no sólo de este caso, sino de cualquier asunto que sea sometido a su conocimiento, está determinado por los alcances que se atribuyan al artículo 1.1 de la Convención ${ }^{6}$. En su consideración, dicho artículo "pone a cargo de los Estados Partes los deberes fundamentales de respeto y garantía, de tal modo que todo menoscabo a los derechos humanos reconocidos en la Convención que pueda ser atribuido (...) a la acción u omisión de cualquier autoridad pública, constituye un hecho imputable al Estado" .

6 El artículo 1.1 de la CADH, en la parte que ahora nos interesa, establece que "los Estados partes en esta Convención se comprometen a respetar los derechos y libertades reconocidos en ella y a garantizar su libre y pleno ejercicio a toda persona (...). Este deber general de respeto encuentra paralelo en otros tratados de derechos humanos, por ejemplo, el artículo 2.1 del Pacto de Derechos Civiles y Políticos, o los artículos 2.1 y 38.1 de la Convención sobre Derechos del Niño.

7 Caso Velásquez Rodríguez contra Honduras, sentencia sobre el fondo de 29 de julio de 1988, fundamento 164 . 
En los términos del artículo 1.1, los Estados parte, al suscribir la Convención Americana, asumen una doble obligación. La primera se refiere al respeto de los derechos y libertades reconocidos en la $\mathrm{CADH}$, mientras que la segunda implica garantizar el libre y pleno ejercicio de los derechos fundamentales a toda persona sometida a su jurisdicción, obligación que no se agota con la existencia de un orden normativo, sino que comporta la necesidad de una conducta gubernamental que asegure la existencia, en la realidad, de una eficaz garantía del libre y pleno ejercicio de los derechos humanos ${ }^{8}$.

En este orden de ideas, resulta claro que, en principio, es imputable al Estado toda violación a los derechos reconocidos por la Convención cometida por un acto del poder público o de personas que actúan prevalidas de los poderes que ostentan por su carácter oficial. No obstante, para la Corte Interamericana no se agotan allí los supuestos en que la responsabilidad del Estado puede verse comprometida a raíz de una lesión a esos derechos. En efecto, "un hecho ilícito violatorio de los derechos humanos que inicialmente no resulte imputable directamente a un Estado, por ejemplo, por ser obra de un particular o por no haberse identificado al autor de la trasgresión, puede acarrear la responsabilidad internacional del Estado, no por ese hecho en si mismo, sino por la falta de la debida diligencia para prevenir la violación o para tratarla en los términos requeridos por la Convención" "?

En esta primera etapa de la jurisprudencia, los derechos fundamentales, a juicio de la Corte, se configuran como límites dirigidos únicamente al actuar de las autoridades; la responsabilidad del Estado, sin embargo, se extiende a aquellos casos en que se demuestre "cierto apoyo o tolerancia del poder público respecto a los particulares en la infracción de los derechos reconocidos en la Convención ${ }^{10}$. Para la Corte resulta irrelevante que los individuos que participaron en el secuestro, tortura y asesinato de Manfredo Velásquez no perteneciesen formalmente a los cuerpos de seguridad del Estado hondureño; lo decisivo, a efectos de determinar la violación de los derechos fundamentales, es que en todos estos casos existe una implicación significativa por parte de las autoridades hondureñas. Si se comprueba dicha implicación —que en términos de la Corte se puede traducir en una falta de debida diligencia, en apoyo, en aquiescencia o en tolerancia - el actuar de los particulares queda equiparado a una actuación de los poderes públicos a efectos del artículo 1.1 de la Convención.

8 Caso Godinez Cruz contra Honduras, sentencia sobre el fondo de 20 de enero de 1989, fundamento, 175; y caso Cantos contra Argentina, sentencia sobre el fondo de 28 de noviembre de 2002, fundamento 49 .

9 Caso Velásquez Rodríguez contra Honduras, sentencia sobre el fondo de 29 de julio de 1988, fundamento 172 (las cursivas son nuestras).

10 Caso Paniagua Morales contra Guatemala, sentencia sobre el fondo de 8 de marzo de 1998, fundamento 91. Este caso también es conocido como de la Panel Blanca, debido a que durante 1987 y 1988 miembros de la Guardia de Hacienda de Guatemala, fuertemente armados, detenían por la fuerza a personas y las obligaban a subir a una furgoneta (panel) blanca. Once de estas personas fueron torturadas y asesinadas y sus cuerpos fueron abandonados pocos días después de su detención en las calles de ciudad de Guatemala y sus alrededores. 
Este tipo de construcción no resulta novedosa en la jurisprudencia comparada. La CIDH hace uso de una buena parte de la extensa batería argumentativa que comprende la doctrina estadounidense de la state action. Al igual que en el caso mexicano y a diferencia del caso europeo continental, en los Estados Unidos de América, la incidencia unidireccional de los derechos fundamentales se mantiene como uno de los pilares más firmes de la teoría constitucional estadounidense. De esta forma, las enmiendas a la Constitución Federal de 1787, las cuales conforman el grupo de derechos o bill of rights del sistema jurídico norteamericano, sólo pueden ser invocadas ante un acto del poder público o state action.

Es fundamental tener en cuenta que la razón que da lugar a este bill of rights es la defensa contra la posible intromisión, en las libertades históricas de los particulares, de una entidad determinada, el poder emergente de la federación, y en específico del poder legislativo. M. Fioravanti señala al respecto que «Sólo en la experiencia estadounidense los modelos historicista e individualista y contractualista recuperan su originaria y común inspiración de garantía contra las filosofías estatalistas y legicéntricas de la Europa continental" ${ }^{11}$. Esto significa que desde los orígenes de la tradición constitucional norteamericana, los derechos son concebidos como una tenencia a preservar del maligno, pero inevitable, surgimiento de los poderes estatales.

De esta forma y en el marco de dichas consideraciones es posible contextualizar el principio por el que las posibles violaciones de derechos fundamentales por parte de particulares, tanto en los aspectos de validez como de eficacia, sean reconducibles al resto del ordenamiento infraconstitucional, principio que por su parte ha tenido una simbiótica aceptación en gran parte del resto del continente.

Ante tal horizonte parecería que la cuestión se encuentra cerrada desde un inicio y que la actividad jurisprudencial se daría a la tarea de aplicar un examen de formalidad estatal a todos aquellos actos violatorios de derechos fundamentales para determinar el subsistema normativo al cual deben ser reconducidos para su adecuada resolución. Sin embargo, fue precisamente el Tribunal Supremo de los Estados Unidos el actor principal en la expansión y experimentación de criterios alternativos al momento de definir la zona de penumbra que conlleva la noción de state action.

Un examen completo de la doctrina de la state action excede los límites de nuestro trabajo ${ }^{12}$. Sin embargo, haremos mención de sus rasgos más dis-

11 M. Fioravanti, Los derechos fundamentales. Apuntes de Historia de las Constituciones, trad. de M. Martínez Neira, Trotta, Madrid, 1998 (1. ${ }^{a}$ ed. 1996), p. 93. En el mismo sentido, véase G. Zagrebelsky, El derecho dúctil, trad. de M. Gascón, Trotta, Madrid, 1997 (1. a ed. 1995), p. 54

12 El estudio más completo de esta materia, en lengua castellana, lo realiza J. M. Bilbao Ubillos, en Los derechos fundamentales en la frontera entre lo público y lo privado, McGraw-Hill, Madrid, 1997. En lengua inglesa resultan imprescindibles las siguientes obras: R. J. Glennon y J. E. Nowak, "State action. Theories for applying constitutional restrictions to activity", en Columbia Law Review, vol. 74, núm. 4 (1974), pp. 656-705; I. Nerken, "A new deal for the protection of fourteenth amendment rights: challenging the doctrinal bases of the civil rights cases and state action 
tintivos, ya que este tipo de respuesta a la Drittwirkung — que evade el problema sustantivo y se concentra en la ampliación del concepto de poder público- es la adoptada por la Corte Interamericana en su primera etapa.

Así, la argumentación contenida en el caso Adickes v. S. H. Kress \& Co (1970) resulta la fuente de la que abreva la CIDH al momento de determinar, en el caso Velásquez Rodríguez, que lo decisivo a efectos de determinar una violación de derechos fundamentales consiste en dilucidar si efectivamente el actuar de los particulares ha contado con el apoyo o tolerancia del poder público. El caso Adickes $v$. Kress ${ }^{13}$, al igual que Truax v. Corrigan ${ }^{14}$, United States v. Price ${ }^{15}$, o Joshua DeShanney v. Winnebago County Department of Social Service $^{16}$, son resoluciones en las que no existe duda respecto a una cuestión: el acto que lesiona los derechos fundamentales proviene de un particular. Sin embargo, la controversia surge al momento de determinar cuál debe ser el grado de participación o implicación de un poder público en el acto del particular, a fin de transformarlo en una state action y, en consecuencia, ser objeto del juicio constitucional.

El caso que nos sirve de guía para ilustrar esta vertiente de la doctrina de la state action se remonta al mes de agosto de 1964, en el que Sandra Adickes, profesora de raza blanca en una escuela de niños de raza negra en Missisipi, decidió ir a almorzar con seis de sus alumnos negros al restaurante del señor Kress. El dueño del local se negó a atender a la mujer, ya que era una persona de raza blanca en compañía de personas de raza negra. Una vez que este grupo decidió abandonar el restaurante, Sandra Adickes fue detenida por la policía ante el alboroto que había provocado al no ser atendida por el señor Kress.

La opinión mayoritaria del Tribunal Supremo, en voz del juez J. M. Harlan, establece, en primer término, que la decimocuarta enmienda no prohíbe a los particulares discriminar por razón de raza, ya que esto es una expresión de sus predilecciones personales que no puede ser limitada por el Estado. Sin embargo, la conclusión sería distinta si la discriminación se produjese por la existencia de una costumbre u ordenanza impuesta o aplicada por las autori-

theory", en Harvard Civil Rights-Civil Liberties Law Review, vol. 12 (1977), pp. 297-366; E. Chemerinsky, "Rethinking State Action" en Northwestern University Law Review, vol. 80, (1985), pp. 503-557; A. R. Madry, «tate action and the obligation of the states to prevent private harm: The Rehnquist transformation and the betrayal of fundamental commitments", en Southern California Law Review, vol. 65, núm. 2 (1992), pp, 781-884; R. J. Krotoszynski, "Back to the briarpatch: an argument in favor of constitutional meta-analysis in state action determinations", en Michigan Law Review, vol. 94, núm. 2 (1995), pp. 302-347; W. Brooks, "The privatization of the civil commitment process and the state action doctrine: have the mentally ill been systematically stripped of their fourteenth amendment rights?", en Duquesne Law Review, vol. 40, núm. 1 (2001), pp. 1-75; y M. Tushnet, "The issue of state action / horizontal effect in comparative constitutional law", en International Journal of Constitutional Law, vol. 1, núm. 1 (2003), pp. 79-98.

13398 U.S. 144 (1970).

14257 U.S. 312 (1921)

15383 U.S. 787 (1966).

16489 U.S. 189 (1989). 
dades en los restaurantes del Estado de Missisipi. Para el Tribunal Supremo, no basta que la segregación sea una costumbre social — como alegaba Adickes-, sino que el demandante debe demostrar que el acusado actuó «bajo apariencia de legalidad de una costumbre o uso del Estado" y con la "implicación" de un funcionario público ${ }^{17}$.

Resulta lógico que el Tribunal Supremo insista en la participación, de cualquier grado, por parte de alguna autoridad, ya que si la simple inactividad por parte del Estado fuera el elemento determinante para definir si existe state action, prácticamente cualquier violación de derechos fundamentales cometida por los particulares sería reconducible al ámbito de los poderes públicos. En el caso concreto, no se acreditó que la segregación racial fuese una práctica implantada por las autoridades locales, sino una simple y lamentable costumbre del dueño del restaurante, por lo que se concluyó que no existía una state action.

Descartar la responsabilidad del Estado es una constante en los casos que de estas características ha conocido el Tribunal Supremo estadounidense, ya que la responsabilidad por omisión del deber de protección del Estado se ha circunscrito a aquellos casos en que las personas estén privadas de libertad bajo la custodia del Estado ${ }^{18}$. La conclusión de la Corte Interamericana, en cambio, será distinta. A partir de estos planteamientos, la CIDH considera que el deber de protección, a cargo de los Estados parte, es de carácter general. Se aplica a todos lo supuestos y a todas las personas sujetas a la jurisdicción de un Estado. Una vez acreditada la tolerancia o inactividad de los poderes públicos, el hecho se refuta como imputable al Estado, por violación al deber previsto en el artículo 1.1 de la Convención ${ }^{19}$.

17 Cfr. Monroe v. Pape [365 U.S. 167 (1961)].

18 Así lo determinó el Tribunal Supremo en el caso DeShanney v. Winnebago de 1988, la última de las resoluciones en las que el máximo tribunal estadounidense abordó este aspecto de la state action. El demandante en este caso fue un menor que había sido víctima de una serie de abusos por parte de su padre, con el que vivía. Los demandados, el Departamento de Servicios Sociales de un condado del estado de Wisconsin, recibieron quejas de que el menor estaba sufriendo abusos a manos de su padre, y pese a que adoptaron diversas medidas para protegerle no intervinieron para retirar al padre la custodia del menor. Finalmente, el padre del demandado le golpeó tan violentamente que éste sufrió daños cerebrales y una severa disminución psíquica. La madre del niño alegó la existencia de una state action, ya que, en su consideración, el conocimiento por parte de las autoridades del condado de Winnebago del peligro que corría el menor creaba una "relación especial" de la que se derivaba un deber de protección a favor del niño. Para el Tribunal Supremo, el deber de protección por parte del Estado emana, no del conocimiento que las autoridades tengan acerca de las dificultades de un individuo o de las declaraciones que realice sobre su intención de ayudarle, sino, únicamente, de las limitaciones que el propio Estado imponga sobre la libertad del individuo, ya sea a través de su encarcelamiento o internamiento en cualquier institución a su cargo. Véase en este sentido, Estelle v. Gamble 429 U.S. 97 (1976); Youngberg v. Romero 457 U.S. 102 (1982); así como el trabajo de D. A. Strauss, "Due process, government inaction, and private wrongs", en Supreme Court Review, vol. 53 (1989), p. 67.

19 Cfr. Caso Gangaram Panday contra Surinam, sentencia sobre el fondo de 21 de enero de 1994 , fundamento 62 . 
En la búsqueda de implicaciones estatales que le permitan extender la responsabilidad del Estado, la Corte Interamericana aborda otra de las parcelas más significativas de la doctrina de la state action: la convalidación por parte del Estado de actos de particulares violatorios de los derechos fundamentales.

Así, para la CIDH, "si el aparato del Estado actúa de modo que tal violación quede impune y no se restablezca, en cuanto sea posible, a la víctima en la plenitud de sus derechos, puede afirmarse que ha incumplido el deber previsto en el artículo 1.1 (...) Esta apreciación es válida cualquiera que sea el agente al cual pueda eventualmente atribuirse la violación, aún los particulares, pues, si sus hechos no son investigados con seriedad, resultarian, en cierto modo, auxiliados por el poder público, lo que comprometería la responsabilidad del Estado" ${ }^{20}$. En este aspecto, el deber de investigar y reparar las violaciones no sólo se entiende referido a las autoridades policiales del Estado, sino que se extiende a los órganos judiciales, por lo que si éstos no reparan en sus sentencias las respectivas violaciones, incumplirán el artículo 1.1 de la Convención y sus actos serán objeto del conocimiento de la Corte Interamericana ${ }^{21}$.

No resulta difícil identificar esta argumentación con la tesis de la eficacia mediata propuesta por el Tribunal Constitucional Federal alemán ${ }^{22}$. En esta línea, los tribunales nacionales, en virtud del artículo 1.1 de la Convención, al determinar el derecho aplicable se encontrarían constreñidos a introducir los contenidos de la Convención Americana y, en caso contrario, la CIDH se vería facultada para examinar los procesos internos en los que no se hubiese atendido a dicho deber.

Con independencia de las implicaciones teóricas que conlleva la tesis de la eficacia medita, y que no abordaremos en este trabajo, el principal problema que acarrea este tipo de posiciones es, de nueva cuenta, que por esta vía

20 Caso Velásquez Rodríguez contra Honduras, sentencia sobre el fondo de 29 de julio de 1988, fundamentos 176 y 177. Es posible identificar un argumento muy similar en el caso Baldeón García contra Perú, sentencia sobre el fondo de 6 de abril de 2006, fundamento 91.

21 Cfr. Caso Villagrán Morales y otros — caso niños de la calle - contra Guatemala, sentencia sobre el fondo de 19 de noviembre de 1999, fundamento 222; y caso Bámaca Velásquez contra Guatemala, sentencia sobre el fondo de 25 de noviembre de 2000, fundamento 188.

22 Conforme a esta tesis, en términos generales, se considera que la concretización de los derechos fundamentales en las relaciones entre particulares se realiza al momento en que el órgano judicial respectivo aplica los derechos fundamentales como parámetros interpretativos al resolver las controversias que se le presentan. A pesar de que cierto sector de la doctrina ha querido ver la asunción de esta tesis en el sistema jurídico español al momento en el que se configura el acceso a la jurisdicción constitucional de este tipo de controversias, lo cierto es que la imputación formal de la violación de los derechos fundamentales a la resolución judicial no responde a la necesidad de implantar o incorporar al derecho fundamental en la controversia objeto de la sentencia, como sucede en el derecho alemán, sino que viene determinada a fin de articular correctamente el acceso de este tipo controversias al recurso de amparo de conformidad con lo previsto en la Ley Orgánica del Tribunal Constitucional español. Véase en este sentido, entre otros, a R. Naranjo de la Cruz, Los límites de los derechos fundamentales en las relaciones entre particulares: la buena fe, Boletín Oficial del Estado y Centro de Estudios Políticos y Constitucionales, Madrid, 2000, p. 208. 
prácticamente cualquier acto de los particulares acarrea la responsabilidad del Estado $^{23}$. En este sentido resultaron las reacciones que en la doctrina estadounidense surgieron frente a la primera construcción jurisprudencial que sostuvo que la intervención judicial, convalidando un acto de un particular, implicaba la responsabilidad estatal: el caso Shelley $v$. Kraemer de 1948. El meollo de este asunto es la posible existencia de una state action por la aplicación judicial de acuerdos particulares que impidan la propiedad o posesión de inmuebles basados en motivos raciales ${ }^{24}$.

El Tribunal Supremo de los Estados Unidos inicia su argumentación recordando que, desde la decisión de los Civil Right Cases de 1883, quedó firmemente establecido que la conducta prohibida por la primera sección de la decimocuarta enmienda constitucional es únicamente aquella que puede, razonablemente, decirse acción de los poderes públicos. La enmienda constitucional no levanta una barrera contra una conducta puramente privada, por errónea o discriminatoria que pudiera ser.

En esta línea, el Tribunal Supremo considera que los acuerdos discriminatorios, por sí mismos, no pueden considerarse violatorios de ningún derecho, siempre y cuando los propósitos de estos convenios se acaten por adhesión voluntaria a sus términos. Sin embargo, la conclusión será distinta si estos convenios se aseguraron únicamente por la imposición que los tribunales estatales hicieron de los términos restrictivos de los convenios.

23 Respecto a la teoría de la eficacia mediata de los derechos fundamentales en las relaciones entre particulares, véase por todos a J. M. Bilbao Ubillos, La eficacia de los derechos fundamentales frente a particulares, Boletín Oficial del Estado y Centro de Estudios Constitucionales, Madrid, 1997, pp. 283-324.

24334 U.S. 1 (1948). Shelley es uno de cuatro casos conocidos colectivamente como los Restrictive Covenant Cases. Los otros tres casos son: McGhee v Sipes, Hurd v. Hodge, y Urciolo $v$. Hodge. El caso Shelley v. Kraemer se origina a partir de los siguientes hechos: el 16 de febrero de 1911, treinta de un total de treinta y nueve propietarios de un inmueble de la ciudad de Saint Louis, Missouri, firmaron y registraron un convenio. Éste establecía que “(...) se restringe el uso y la ocupación de la propiedad mencionada por el término de cincuenta años a partir de esta fecha, de manera que se establece la condición, en todo tiempo y para las subsecuentes transmisiones, de adherir al terreno, en forma precedente a su venta, la condición de que ninguna parte o fracción de dicha propiedad será ocupada, por el término mencionado de cincuenta años, por ninguna persona que no sea de la raza caucásica, pues se intenta evitar el uso de la propiedad señalada por personas de las razas negra o mongólica». En agosto de 1945, como consecuencia de un contrato de compraventa, los promoventes, de raza negra, -mediante una considerable suma - recibieron, de uno de los propietarios, una escritura en la que se garantiza el título de propiedad sobre parte del predio en cuestión. El tribunal que conoció del caso encontró que los promoventes no tuvieron conocimiento del convenio restrictivo al tiempo de la compra. En octubre de 1945, propietarios de otras partes del inmueble sujetos a los términos del convenio restrictivo, demandaron en el Tribunal de Circuito de la ciudad de Saint Louis que se impidiera a los negros tomar posesión del predio, y que se les privara del título de propiedad y se le revirtiera al vendedor, o a quien el tribunal determinase. El tribunal negó la petición, con base en que el convenio restrictivo nunca llegó a ser definitivo y completo, ya que fue intención de las partes que no entraría en vigor hasta que fuese firmado por todos los propietarios, y nunca se obtuvieron las firmas de todos ellos. El Tribunal Superior de Missouri revocó esta última resolución. 
En el caso concreto, resulta claro que, de no ser por la intervención activa de los tribunales estatales, los promoventes hubieran sido libres de ocupar la propiedad, sin restricción alguna. Para el Tribunal Supremo, el caso Shelley no es de aquellos casos — como se ha sugerido— en que los poderes públicos se limiten a abstenerse de actuar, dejando en libertad a los particulares para imponer las discriminaciones que les plazcan. Se trata, más bien, de un caso en el que los tribunales han puesto a disposición de los particulares toda la potestad coercitiva del Estado para negar a los promoventes, con base en la raza o el color, el disfrute de los derechos de propiedad en terrenos que los promoventes querían y podían adquirir y que los vendedores estaban dispuestos a vender. La diferencia entre imponer en estos casos, coactivamente o no y por vía judicial, los convenios restrictivos, significa para los promoventes la diferencia entre serles negados los derechos de propiedad asequibles a otros miembros de la comunidad y el concederles el pleno disfrute de esos derechos sobre una base de igualdad. En consecuencia, son los órganos judiciales quienes han violentado la protección igual de las leyes, garantizada por la decimocuarta enmienda constitucional.

Este fallo, que en un principio causó gran conmoción y un torrente de comentarios, sentaba las bases para una verdadera revolución de la doctrina de la state action. La resolución del Tribunal Supremo implicaba, en la práctica, la aceptación de la vigencia de los derechos fundamentales en las relaciones privadas en un plano sustantivo. A pesar de que en la sentencia se enfatiza que la ejecución del pacto discriminatorio por parte del órgano judicial es determinante, lo que en realidad viene a decir Shelley $v$. Kraemer es que la validez de los pactos particulares depende de su debida conformidad con el bill of rights, ya que en caso contrario, no serán convalidados por los tribunales ${ }^{25}$. En consecuencia, y ante el peligro que representaba para la unidireccionalidad de los derechos el aceptar en todas sus consecuencias esta doctrina, la jurisprudencia constitucional estadounidense decide desmarcarse de este precedente en resoluciones como Black v. Cutter Laboratories ${ }^{26}$ y Evans v. Abney ${ }^{27}$.

La Corte Interamericana, en una etapa en la que todavía existen dudas sobre la multidireccionalidad de los derechos fundamentales, es consciente de estos riesgos. Aunado a lo anterior, su mayor preocupación y lo que en último termino producirá el abandono de la tesis de la mediación judicial, es que una doctrina de este tipo convertiría a la CIDH en una especie de tribunal de apelaciones de las sentencias de los órganos judiciales internos. Situación que provocaría graves roces con los Estados parte, que se aleja radicalmente de su naturaleza y fines propios, y de la cual ha sido consciente la CIDH desde sus primeras sentencias ${ }^{28}$.

25 Cfr. H. Wechsler, "Toward neutral principles of Constitutional Law", en Harvard Law Review, vol. 73 (1959), p. 29; y D. Kennedy, "The stages of decline of the public/private distinction", en University of Pennsylvania Law Review, vol. 130 (1982), p. 1352.

26351 U.S. 292 (1956)

27396 U.S. 435 , 445 (1970).

28 En este sentido, véase caso Suárez Rosero contra Ecuador, sentencia sobre el fondo de 12 de noviembre de 1997, fundamento 37; caso Garrido y Baigorria contra Argentina, sentencia sobre reparaciones de 27 de abril de 1998, fundamento 24; y caso Cesti Hurtado contra Perú, sentencia sobre las excepciones preliminares de 26 de enero de 1999, fundamento 47. 
Por este motivo, la responsabilidad estatal por vía de la convalidación judicial y, en general, la búsqueda de implicaciones estatales, es abandonada por la Corte Interamericana como el elemento determinante para determinar la vigencia de los derechos fundamentales en las relaciones privadas ${ }^{29}$. Un importante número de casos, que llegan a su conocimiento a principios de nuestra década y en los que de forma manifiesta es un particular el que lesiona los derechos fundamentales, obligarán a la Corte a explorar nuevos caminos en esta materia.

\section{LA PRIMERA APROXIMACIÓN A LA DRITTWIRKUNG: LOS DERECHOS FUNDAMENTALES COMO OBLIGACIONES ERGA OMNES}

La Corte Interamericana inaugurará, a partir del caso Blake contra Guatemala, una etapa de su jurisprudencia en la que el estudio del carácter de la norma violada se convertirá en el argumento de fondo para afirmar la Drittwirkung de los derechos previstos en la Convención.

En marzo de 1985, dos ciudadanos estadounidenses fueron asesinados en Guatemala a manos de las denominadas Patrullas de Autodefensa Civil ${ }^{30}$. La Comisión Interamericana sometió el caso a la CIDH a fin de que determinara la responsabilidad de Guatemala bajo el argumento de que las "patrullas civiles" actuaron como agentes del Estado. El gobierno guatemalteco, curtido por las diversas condenas que había recibido en los casos de desaparición de activistas políticos por miembros de la policía secreta, planteó una estrategia distinta a fin de evadir su responsabilidad. En su consideración, la CIDH resultaba incompetente para conocer de la desaparición de los ciudadanos estadounidenses en virtud de que los hechos en que se fundamentaba la demanda constituían "un ilícito penal del orden común, como es el homicidio calificado o asesinato, y no un caso de violación de derechos humanos, como son el derecho a la libertad personal y el derecho a la vida ${ }^{31}$.

29 En los últimos años sólo hemos logrado identificar tres casos relevantes en los cuales la CIDH haya determinado la responsabilidad del Estado por haber dado cobertura, de forma pasiva, a los actos de los particulares. Véase en este sentido, Juan Humberto Sánchez contra Honduras (sentencia sobre el fondo de 7 de junio de 2003); 19 Comerciantes contra Colombia (sentencia sobre el fondo de 5 de julio de 2004); y Masacres de Ituango contra Colombia (sentencia sobre el fondo de 1 de julio de 2006).

30 Nicholas Chapman Blake, periodista, y Griffith Davis, fotógrafo, residentes en Guatemala, partieron el día 26 de marzo de 1985 rumbo a una pequeña aldea al sur del país. El objetivo del viaje era recabar información para escribir un artículo sobre uno de los sectores de la guerrilla guatemalteca. Ese mismo día fueron interceptados por la Patrulla de Autodefensa Civil de El Llano, una organización paramilitar formada por campesinos e indígenas que efectuaba labores de patrullaje, defensa y control del movimiento guerrillero. Años más tarde se determinó que los miembros de esta patrulla trasladaron a los estadounidenses a un lugar despoblado para asesinarles e incinerar sus cuerpos para evitar que fueran descubiertos.

31 Cfr. Caso Blake contra Guatemala, sentencia sobre las excepciones preliminares de 2 de julio de 1996, fundamento 25. El Estado guatemalteco argumentó que las Patrullas civiles eran or- 
La CIDH, al momento de fallar este asunto, consideró que las patrullas civiles actuaban, efectivamente, como agentes del Estado, ya que recibían recursos, armamento, entrenamiento y, en ocasiones, órdenes directas del Ejército guatemalteco. La aquiescencia del Estado en relación a las actividades de estos grupos paramilitares permite extender la responsabilidad a las autoridades guatemaltecas. Sin embargo, varias interrogantes planean sobre la argumentación de la Corte. Este órgano es consciente que en ocasiones resultará imposible demostrar un estado general de impunidad respecto a este tipo de hechos, considerar que las violaciones denunciadas son atribuibles a una política de Estado o, simplemente, acreditar una conexión, por mínima que sea, con los poderes públicos. A estas directrices responden una serie de resoluciones en las que Colombia es demandada por diversas violaciones de derechos fundamentales perpetradas por guerrilleros y paramilitares, a pesar de una política activa y decidida, tanto de los cuerpos policiales como de los órganos judiciales de ese país, en contra de estos grupos.

La búsqueda de soluciones alternativas para este tipo de casos tiene un protagonista fundamental: el brasileño A. A. Cançado Trindade. Este juez de la $\mathrm{CIDH}$, electo en 1994, emitirá un voto razonado en el caso Blake contra Guatemala que será la base para consagrar la vigencia de los derechos fundamentales en las relaciones privadas.

A juicio de Cançado, es necesario desmitificar la presentación, frecuente e indebida, de ciertos postulados como verdades eternas e inmutables, cuando son, más bien, producto de su tiempo, o sea, soluciones jurídicas encontradas en una determinada etapa de la evolución de derecho, conforme a las ideas prevalecientes en la época. Una de estas ideas es la que representa a los tratados internacionales como normas que limitan únicamente la actuación de los poderes públicos. Los tratados de derechos humanos, por el contrario, consagran obligaciones de carácter objetivo y representan estándares de comportamiento dirigidos a la creación de un ordre public internacional ${ }^{32}$. En su consideración, el carácter absoluto de la autonomía de la voluntad ya no puede ser invocado ante la existencia de normas del jus cogens, como son los derechos fundamentales previstos en la $\mathrm{CADH}$, que se configuran como obligaciones erga omnes de protección y, en consecuencia, son el contenido mínimo de expresión de todas las relaciones jurídicas de los ordena-

ganizaciones comunitarias voluntarias que se originaron en las áreas de conflicto y que se encontraban integradas por los pobladores de esas zonas con el propósito de defender sus vidas y sus pertenencias contra la subversión. Señaló que era natural que dichas patrullas tuvieran vinculaciones estrechas con el Ejército, pero que eso no permitía presumir que sus integrantes pertenecieran o tuvieran iguales funciones que las Fuerzas Armadas, ya que los miembros de las patrullas no recibían remuneración alguna ni estaban sujetas a la disciplina militar.

32 Caso Blake contra Guatemala, voto razonado del juez Cançado a la sentencia sobre el fondo de 24 de enero de 1998, fundamentos 20 a 29, y voto razonado del juez Cançado a la sentencia sobre reparaciones de 22 enero de 1999, fundamentos 24 y 27; caso Las Palmeras contra Colombia, voto razonado del juez Cançado a la sentencia sobre excepciones preliminares de 4 de febrero de 2000, fundamento 7 . 
mientos nacionales, incluidas aquellas que se suceden entre actores no estatales $^{33}$.

La argumentación de Cançado será adoptada por la totalidad de los jueces de la CIDH en el caso de la Comunidad de Paz de San José de Apartadó contra Colombia de 2002. En este asunto, revelador de la tragedia a la que vive sometida la sociedad colombiana, resulta incuestionable que los autores de más de cincuenta asesinatos en un período de nueve meses, son miembros de un grupo paramilitar denominado Autodefensas Unidas de Colombia. A juicio de la Corte, la obligación general de respeto de los derechos fundamentales, prevista en el artículo 1.1 de la Convención, para ser eficaz, «se impone no sólo en relación con el poder del Estado, sino también en las relaciones entre particulares (grupos clandestinos, paramilitares, u otros grupos de particulares), ${ }^{34}$.

En esta resolución se establece que el desarrollo jurídico de las obligaciones erga omnes partes de protección asume una importancia cada vez mayor, sobre todo frente a la diversificación de las fuentes de violaciones de los derechos humanos - tan evidente en una situación de conflicto armado interno como en el caso de la Comunidad de Paz-. Este nuevo escenario requiere, a juicio de la Corte, "el reconocimiento de los efectos de la Convención Americana vis-à-vis terceros (la Drittwirkung), ,35.

Reconocimiento que, a partir del año 2003, se efectúa en todos aquellos casos en los que la Corte aborda una lesión de derechos fundamentales acaecida en una relación entre particulares. Así, en los casos de las Comunidades del Jiguamiandó y del Curbaradó contra Colombia, del Pueblo indígena de Kankuamo contra Colombia, o en el del Pueblo indígena de Sarayaku contra Ecuador, la Corte insiste en que los Estados parte se encuentran conminados a atender «al amplio alcance de las obligaciones erga omnes de protección (...), caracterizadas por el jus cogens, del cual emanan, como normas de carácter objetivo que abarcan a todos los destinatarios de las normas jurídicas, tanto a los integrantes de los órganos del poder público estatal como a los particulares ${ }^{36}$.

33 Caso Personas haitianas y dominicanas de origen haitiano en la República Dominicana, voto razonado del juez Cançado a la solicitud de medidas provisionales de 7 de agosto de 2000, fundamento 25 .

34 Caso Comunidad de Paz de San José de Apartadó contra Colombia, resolución sobre medidas provisionales de 18 de junio de 2002, fundamento 11, y resolución sobre medidas provisionales de 17 de noviembre de 2004, fundamento 13. El caso de la Comunidad de Paz no sólo resulta relevante a efectos del objeto de nuestro trabajo, sino que también representa un hito en la jurisprudencia interamericana, ya que se admite por primera vez que las medidas provisionales que puede otorgar la Corte alcancen a una pluralidad de personas que, aunque no se les individualice previamente, estén colocadas, potencialmente, en la situación de ser víctimas. Véase respecto a la problemática colombiana el interesante trabajo de A. Seagrave, "Conflict in Colombia: how can rebel forces, paramilitary groups, drug traffickers, and government forces be held liable for human rights violations in a country where impunity reigns supreme?", en Nova Law Review, vol. 25, núm. (2001), pp. 525-546.

35 Caso Comunidad de Paz (...) contra Colombia, voto concurrente del juez Cançado a la resolución sobre medidas provisionales de 18 de junio de 2002, fundamento 14 .

36 Caso de las Comunidades del Jiguamiandó y del Curbaradó contra Colombia, resolución sobre medidas provisionales de 6 de marzo de 2003, considerando 11, y resolución sobre medidas 
La relación entra las normas de jus cogens y las obligaciones erga omnes, aspectos centrales en la argumentación de la Corte, no será debidamente abordada hasta la Opinión Consultiva 18/03, resolución que da origen a la tercera etapa de la jurisprudencia de la Corte en esta materia, por lo que nos remitimos al siguiente apartado respecto a esta cuestión. Por ahora, sólo nos importa dejar constancia de que en esta fase, la multidireccionalidad es, a juicio de la Corte, un rasgo que se puede predicar de todo el catálogo de derechos fundamentales de la Convención Americana.

Por último, no debe llevar a confusión el hecho de que, en todos estos casos, la Corte Interamericana, en los puntos resolutivos de las sentencias, condene a los Estados a adoptar las medidas necesarias para la protección y garantía de los derechos fundamentales violados. La imputación instrumental de la violación a los órganos públicos nacionales sólo cumple una función procesal, a fin de articular correctamente el procedimiento contencioso previsto en los artículos 61 y 62 de la CADH. Sin embargo, el juicio que realiza la Corte Interamericana en esta segunda etapa de la jurisprudencia versa, invariablemente, sobre la adecuación de las actuaciones de los particulares a los derechos fundamentales previstos en la Convención Americana. Una vez que ha determinado la existencia de una violación de este tipo, reitera la multidireccionalidad de los derechos exigida directamente por el artículo 1.1 de la $\mathrm{CADH}$, y conmina a los Estados a restituir el derecho violado a través de los medios que sean necesarios para cada caso concreto ${ }^{37}$.

La imputación directa a los particulares de la violación de los derechos fundamentales es una constante desde el año 2003. Esta situación quedará definitivamente asentada en la Opinión Consultiva 18/03, el verdadero leading case de la doctrina interamericana de la Drittwirkung.

\section{LA EFICACIA DIRECTA DE LOS DERECHOS FUNDAMENTALES DE LA CONVENCIÓN AMERICANA: LA OPINIÓN CONSULTIVA $18 / 03$}

El 10 de mayo de 2002, México, con fundamento en el artículo 64.1 de la $\mathrm{CADH}$, sometió a la Corte Interamericana una solicitud de opinión consultiva. De acuerdo con lo dispuesto en la propia Convención, la CIDH posee dos atri-

provisionales de 15 de marzo de 2005, considerando 8; caso del Pueblo indígena de Kankuamo contra Colombia, resolución sobre medidas provisionales de 5 de julio de 2004, considerando 11; y caso del Pueblo indigena de Sarayaku contra Ecuador, resolución sobre medidas provisionales de 6 de julio de 2004, considerando 10. En este último caso resulta importante resaltar que el particular que comete la violación ya no es un grupo guerrillero o paramilitar, sino una simple empresa: la Compañía General de Combustible de Argentina. Al personal de seguridad de esta empresa, que realiza explotaciones petroleras en tierras de la comunidad indígena kichwa, se le imputa la violación del derecho de circulación en detrimento de los miembros de este pueblo indígena.

37 En este sentido, caso Caballero Delgado y Santana contra Colombia, sentencia sobre el fondo de 8 de diciembre de 1995, fundamento 69; caso Suárez Rosero contra Ecuador, sentencia 
buciones esenciales. La primera, en la cual se enmarcan todos los casos que hemos estudiado hasta el momento, es de carácter jurisdiccional o contencio$s a$. Mediante esta atribución, la Corte es competente para conocer de cualquier caso relativo a la interpretación y aplicación de las disposiciones de la Convención que le sea sometido, siempre que los Estados parte en el caso hayan reconocido dicha competencia. La segunda atribución es de naturaleza consultiva. Los Estados miembros de la Organización de Estados Americanos podrán consultar a la Corte acerca de la interpretación de la Convención o de otros tratados concernientes a la protección de los derechos humanos en los Estados americanos, así como sobre la compatibilidad entre cualquiera de sus leyes internas y los mencionados instrumentos internacionales ${ }^{38}$.

En el ejercicio de su función consultiva, la Corte no está llamada a resolver cuestiones de hecho, sino a desentrañar el sentido, propósito y razón de las normas internacionales sobre derechos humanos. En este sentido, y a diferencia de las sentencias dictadas en ejercicio de la función contenciosa, no existe controversia alguna respecto a los efectos jurídicos vinculantes de las "opiniones" de la Corte. A juicio de la doctrina, y de la propia Corte Interamericana, la obligatoriedad de las Opiniones Consultivas respecto a todos los Estados miembros, hayan o no solicitado dicha opinión, está dada por el instrumento internacional que interpretan, es decir, al interpretar un tratado, dicha interpretación tiene el mismo valor y fuerza jurídica que el texto del tratado interpretado ${ }^{39}$.

Desde el año 1982, la Corte Interamericana ha emitido diecinueve opiniones consultivas, de las cuales dos han sido solicitadas por el gobierno me-

sobre el fondo de 12 de noviembre de 1997, fundamento 107; y caso Castillo Petruzzi y otros contra Perú, sentencia sobre el fondo de 30 de mayo de 1999, fundamento 220.

38 La propia Corte ha señalado que, a través de esta competencia, puede abordar la interpretación de un tratado siempre que esté directamente implicada la protección de los derechos humanos en un Estado miembro del sistema interamericano, aunque dicho instrumento no provenga del mismo sistema regional de protección (Véase, por todas, la Opinión Consultiva 1/82, de 24 de septiembre de 1982, solicitada por Perú, relativa al objeto de la función consultiva de la Corte, fundamento 38). En este sentido, véanse los trabajos de M. Ventura Robles y D. Zovatto, $L a$ función consultiva de la Corte Interamericana de derechos humanos: naturaleza y principios, 1982-1987, Civitas e Instituto Interamericano de Derechos Humanos, Madrid, 1989; J. M. Pasqualucci, "Advisory practice of the Inter-american Court of Human Rights: contributing to the evolution of international human righst law", en Stanford Journal of International Law, vol. 38, núm. 2 (2002), pp. 241-288; y P. Nikken, "La función consultiva de la Corte Interamericana de Derechos Humanos", en El sistema interamericano de protección de los derechos humanos en el umbral del siglo XXI, t. I, Corte Interamericana de Derechos Humanos, San José de Costa Rica, 2003, pp. 161184.

39 Cfr. Opinión Consultiva 18/03, cit., fundamento 60. En este sentido véase, C. de Silva Nava, "La jurisprudencia, interpretación y creación del Derecho", en Isonomía. Revista de Teoría y Filosofía del Derecho, núm. 5 (1996), p. 22; H. Faúndez Ledesma, El sistema interamericano de protección de los derechos humanos. Aspectos institucionales y procesales, Instituto Interamericano de Derechos Humanos, San José de Costa Rica, 1996, p. 453; C. Martín, "La Corte Interamericana de Derechos Humanos: funciones y competencia", en Derecho internacional de los derechos bumanos, México, 2004, p. 266; y L. Ortiz Ahlf, "Fuentes del derecho internacional de los derechos humanos", en Derecho internacional de los derechos humanos, cit., p. 47. 
xicano: en 1999, la relativa al derecho a la información sobre la asistencia consular en el marco de las garantías del debido proceso y, la segunda, en el año 2002, relativa a la condición jurídica y derechos de los migrantes. Este último procedimiento consultivo, que será el objeto de nuestro estudio, ha generado la mayor movilización en la historia de la Corte ${ }^{40}$. El motivo, una sentencia del Tribunal Supremo de los Estados Unidos de América.

En marzo de 2002, el Tribunal Supremo estadounidense decidió, en el caso Hoffman Plastic Compounds v. National Labor Relations Board, que un trabajador indocumentado no tenía derecho al pago de salarios caídos o de tramitación, después de ser despedido ilegalmente por intentar ejercer derechos otorgados por la legislación laboral, la National Labor Relations Act ${ }^{11}$. El Tribunal Supremo sostuvo que la prohibición de trabajar sin autorización, prevista en la Ley de inmigración, prevalecía sobre el derecho de formar y ser parte de un sindicato ${ }^{42}$.

La decisión en el caso Hoffman Plastic Compounds fue adoptada por mayoría de 5 a 4 votos. El autor del voto disidente de la minoría fue el juez S. G. Breyer, el último de los miembros del Tribunal nombrado en la era Clinton. Éste señaló que permitir a los migrantes en situación irregular el acceso a los mismos recursos legales que tienen los ciudadanos es la única forma de ase-

40 El procedimiento contó con la participación de doce estados americanos, la Comisión Interamericana, la Agencia de las Naciones Unidas para los Refugiados, el Consejo Centroamericano de Procuradores de Derechos Humanos, y nueve entidades de la sociedad civil y de la academia de diversos países de la región.

41535 U.S. 137 (2002). Este caso involucra a José Castro, un mexicano contratado en la planta de la compañía Hoffman Plastic Compounds, ubicada en un suburbio de Los Ángeles, California. En 1989, cuando el señor Castro contribuyó a organizar un sindicato para mejorar las condiciones de trabajo en la planta fue despedido. En enero de 1992 la National Labor Relations Board (NLRB) decidió que tal despido era ilegal y ordenó el pago de salarios caídos (back pay), y la reinstalación del señor Castro. En junio de 1993, durante la audiencia realizada ante un juez administrativo de la $N L R B$ para determinar el monto del pago de salarios caídos o de tramitación, el señor Castro declaró que nunca había sido admitido legalmente ni autorizado para trabajar en los Estados Unidos. Debido a esta declaración, el juez administrativo decidió que no se podía otorgar el pago de los salarios caídos, ya que ello estaría en conflicto con la Inmigration Control and Reform Act de 1986. Esta ley prohíbe que los empresarios contraten a trabajadores indocumentados, con conocimiento de ello, y que los empleados utilicen documentos falsos para ser contratados. En septiembre de 1998 la NLRB revocó la decisión del juez administrativo e indicó que la forma más efectiva de fomentar las políticas de inmigración consistía en proporcionar a los trabajadores indocumentados las mismas garantías y recursos que la legislación laboral otorga a los demás empleados. La NLRB decidió que aunque el trabajador indocumentado no tenía derecho a ser reintegrado, se le debían pagar los salarios caídos y los intereses acumulados por los 3 años de trabajo perdido, cantidad que ascendía a los 67.000 dólares. En 2001, la Corte Federal de Apelaciones denegó la solicitud de revisión presentada por la compañía y confirmó la decisión de la $N L R B$.

42 Esta decisión sigue la línea marcada por el caso Sure-Tan v. National Labor Relations Board [467 U.S. 883 (1984)], en el cual se estableció que los trabajadores pueden ser entregados al Servicio Nacional de Inmigración y Naturalización, aún cuando el motivo del empleador para hacerlo sea el ejercicio de una represalia ilegal en contra de un trabajador dedicado a una actividad protegida por la legislación laboral. 
gurar la protección de sus derechos. El Juez Breyer analizó cuidadosamente el posible impacto de la decisión sobre los trabajadores en situación irregular, indicando que si los trabajadores indocumentados no pueden recibir el pago de salarios caídos al ser despedidos ilegalmente, los empleadores despedirán a tales trabajadores cuando intenten sindicalizarse, ya que no habrá consecuencia alguna para el empleador, al menos en la primera vez que utilice este método ${ }^{43}$.

Cálculos conservadores sugieren que hay al menos 5.3 millones de migrantes en situación irregular trabajando en los Estados Unidos, y que 3 millones de ellos provienen de México. Frente a tal escenario, la alarma fue inmediata en el gobierno mexicano, más aún si se tiene en cuenta que las remesas de dinero que los mexicanos residentes en los Estados Unidos mandan a sus familias en México constituye uno de los mayores ingresos de la economía mexicana.

Así pues, sólo dos meses después del fallo recaído en el caso Hoffman Plastic Compounds, el gobierno mexicano decidió solicitar una opinión consultiva a fin de que la Corte Interamericana dilucidara diversas cuestiones que implicaban la interpretación del principio de igualdad y del deber de respeto de los derechos fundamentales previstos en la Convención Americana. El gobierno mexicano, en su escrito de observaciones, no hace referencia expresa a la sentencia del Tribunal Supremo, aunque resulta patente que el escrito está estructurado como contestación a cada uno de los puntos resueltos por el máximo tribunal estadounidense.

Resulta irónico que el gobierno mexicano, en lo que nos interesa, haya señalado que "el individuo puede ser sujeto activo de obligaciones en materia de derechos humanos, así como responsable en lo individual de su incumplimiento (...) ya que tratándose de normas fundamentales, reveladas a través de manifestaciones objetivas, y siempre que no exista duda en cuanto a su vigencia, el individuo como podría ser un empleador, está obligado a respetarlas, sin importar las medidas de carácter interno que el Estado haya tomado para asegurar, o incluso para vulnerar, su cumplimiento " ${ }^{44}$. Es irónico ya que el sistema jurídico mexicano está estructurado bajo la idea de que los derechos fundamentales son límites dirigidos únicamente al poder público ${ }^{45}$.

La perplejidad no se produce sólo por las anteriores afirmaciones. En el mismo escrito de consideraciones, una vez que el gobierno mexicano se arroga el título de "defensor de los derechos humanos de los trabajadores migrantes", señala que a pesar sus esfuerzos, "no ha podido evitar el recrudecimiento de legislaciones y prácticas discriminatorios contra el extranjero en un

43 Es importante mencionar que la decisión, en el caso en estudio, deja intacto el derecho a un salario mínimo y al pago de horas extra, de acuerdo con la Fair Labor Standards Act, ya que sólo se refirió al pago de salarios caídos por trabajo no realizado.

44 Opinión Consultiva 18/03, cit., párrafo 19.

45 Véase al respecto, J. Mijangos y González, Los derechos fundamentales en las relaciones entre particulares. Análisis del caso mexicano, cit., pp. 70-143. 
país distinto al suyo, ni la regulación del mercado de trabajo con base en criterios discriminatorios, acompañados de xenofobia", en clara alusión a los Estados Unidos ${ }^{46}$. El gobierno mexicano parece olvidarse de su patio sur, en el cual miles de centroamericanos, camino hacia los Estados Unidos, sufren constantemente un sinfín de penurias y vejaciones a manos de los funcionarios mexicanos, situación que ha sido constatada, in situ, hace pocos años por una Comisión del Senado de la República ${ }^{47}$. En cualquier caso, estas cuestiones desbordan el objeto de la investigación, por lo que procederé, en primer término, a analizar la argumentación vertida por la Corte Interamericana.

La Corte considera que a partir de las consideraciones planteadas por el gobierno mexicano debe abordar las siguientes cuestiones: 1) la obligación de respetar y garantizar los derechos humanos y el carácter fundamental del principio de igualdad y no discriminación, 2) la aplicación de dicho principio a los migrantes, 3) los derechos de los trabajadores migrantes indocumentados, y 4) las obligaciones estatales en la determinación de las políticas migratorias a la luz de los instrumentos internacionales de protección de los derechos humanos. Nuestro estudio se centrará en el segundo y tercer puntos, los cuales contienen un buen número de argumentos que permiten afirmar la eficacia directa de los derechos fundamentales en las relaciones privadas.

La primera operación que realiza la CIDH se encamina a determinar si el principio de igualdad y no discriminación puede ser calificado como de jus cogens. A su juicio, dicho principio, al igual que en sentencias anteriores lo había hecho respecto al derecho a la vida, a la integridad personal o a la libre circulación de personas, puede considerase, efectivamente, como imperativo del derecho internacional general, "en cuanto es aplicable a todo Estado, independiente de que sea parte o no en determinado tratado internacional, y genera efectos con respecto a terceros, inclusive a particulares (...) ya que sobre él descansa todo el andamiaje jurídico del orden público nacional e internacional y es un principio fundamental que permea todo ordenamiento jurídico ${ }^{48}$.

46 Opinión Consultiva 18/03, cit., párrafos 12 y 13.

47 Los días 12 y 13 de agosto de 2004, la Comisión de Derechos Humanos del Senado de la República realizó una visita a la frontera sur mexicana, con el objeto de constatar la situación de los migrantes centroamericanos en el Estado de Chiapas. Según el informe elaborado por el Senado, sólo en el primer semestre de 2004 se denunciaron más de 1.500 violaciones de derechos fundamentales cometidas por las fuerzas del orden mexicano, entre las que destacan la detención irregular, los tratos crueles, inhumanos y degradantes, el cohecho pasivo, el robo agravado, la estafa, y las agresiones por parte de diversas autoridades. Se denunciaron también violaciones laborales cometidas por los particulares, consistentes en jornadas inhumanas de trabajo, retención de documentos personales y salario, engaño, maltrato verbal y físico, y amenazas de entregar a los centroamericanos a las autoridades migratorias mexicanos (Gaceta Parlamentaria, 13 de septiembre de 2004, núm. 58, 2004). Respecto a la corresponsabilidad del Estado mexicano en la migración de sus nacionales hacia los Estados Unidos, véase el interesante estudio de J. A. Bustamante, Migración internacional y derechos humanos, Universidad Nacional Autónoma de México, México, 2004.

48 Opinión Consultiva 18/03, cit., fundamentos 100 y 101. En el mismo sentido de considerar al principio de igualdad y no discriminación como de jus cogens, véase el caso Yatama v. Nicaragua, sentencia sobre el fondo de 23 de junio de 2005, fundamentos 184 y 185 . Este caso des- 
Desde la etapa anterior, el hecho de que una norma perteneciese al jus cogens había sido considerado por la Corte como el primer elemento que nos permite identificar la multidireccionalidad de una norma. Sin embargo, no había explicitado las características de ese jus cogens. Tradicionalmente vinculado con la noción de orden público internacional, el concepto de jus cogens supone que existen algunas normas tan fundamentales para la comunidad internacional que los Estados no pueden derogarlas. Este concepto fue definido por primera vez, en un instrumento internacional, en el artículo 53 de la Convención de Viena de 1969 sobre el Derecho de los Tratados, según el cual «una norma imperativa de derecho internacional general es una norma aceptada y reconocida por la comunidad internacional de Estados en su conjunto como norma que no admite acuerdo en contrario y que sólo puede ser modificada por una norma ulterior de derecho internacional general que tenga el mismo carácter ${ }^{49}$. Sin embargo, el jus cogens no se ha limitado al derecho de los tratados. Su dominio se ha ampliado, alcanzando también el derecho internacional general, y abarcando todos los actos jurídicos. Así lo entiende la Corte Interamericana, al señalar que la verdadera virtualidad de este concepto, hoy en día, se aprecia en la responsabilidad internacional de los Estados.

Una vez que la Corte realiza el repaso de las resoluciones internacionales más importantes en esta materia ${ }^{50}$, establece que los derechos fundamentales

taca, a su vez, por ser la primera ocasión en la que la CIDH aborda de forma directa el tema de los derechos políticos. Con posterioridad a la Opinión Consultiva 18/03, es posible identificar una serie de resoluciones en las que otro derecho fundamental, la prohibición de la tortura física o psicológica, se ha consolidado como una norma de jus cogens. Véase en este sentido, entre otros, el caso Hermanos Gómez Paquiyauri contra Perú, sentencia sobre el fondo de 8 de julio de 2004, fundamento 112; y caso Baldeón García contra Perú, sentencia sobre el fondo de 6 de abril de 2006, fundamento 35.

49 Por su parte, el artículo 64 de la misma Convención se refiere al jus cogens supervenien$t e$, al señalar que "si surge una nueva norma imperativa de derecho internacional general, todo tratado existente que esté en oposición con esa norma se convertirá en nulo y terminarám. Entre las obras de obligada referencia sobre este tema destacan, A. Verdross, "Jus dispositivum and jus cogens in international law", en American Journal of International Law, vol. 60 (1966), pp. 55-63; E. Suy, "The concept of jus cogens in public international law", en Lagonissi Conference on International Law, Ginebra, 1967, pp. 17-77; A. Gómez Robledo, "Le ius cogens international: sa genèse, sa nature, ses fonctions", en Recueil des Cours de l'Académie de Droit International de La Haye, vol. III (1981), pp. 9-217. Asimismo, véanse los trabajos de R. St. J. Macdonald, "Fundamental norms in contemporary international law", en Canadian Yearbook of International Law, vol. XXV (1987), pp. 115-149; G. A. Christenson, "Jus cogens: guarding interests fundamental to international society", en Virginia Journal of International Law, vol. 28 (1988), pp. 585-628; y G. M. Danilenko, "International jus cogens: Issues of law-making", en European Journal of International Law, vol. 2 (1991), pp. 42-65.

50 Véase la Opinión consultiva de la Corte Internacional de Justicia sobre Reservas a la Convención para la prevención y la sanción del delito de genocidio de 28 de mayo de 1951, ICJ Reports 1951, p. 15; el caso Barcelona Traction, Light and Power Company Limited (Bélgica v. España), ICJ Reports 1970, p. 3; el caso sobre Aplicación de la Convención para la prevención y la sanción del delito de genocidio (Bosnia-Herzegovina $v$. Yugoslavia) (objeciones preliminares) ICJ Reports 1996, p. 595; y el caso Prosecutor v. Anto Furndzija, IT-95-17/1-T, sentencia de 10 de diciembre de 1998 del Tribunal Penal Internacional para la ex Yugoslavia, párrafos 137-146 y 153157. 
previstos en la Convención son normas de jus cogens, pero no sólo porque, en palabras de A. Gómez Robledo, representan la expresión jurídica de la propia comunidad internacional como un todo, sino porque, además, así lo han determinado los propios Estados miembros al establecer la obligación de respetar y garantizar los derechos humanos prevista en el artículo 1.1 de la Convención ${ }^{51}$. Es a través de la unión de estos dos factores como los derechos fundamentales de la CADH se convierten en el orden público interamericano, en normas imperativas del sistema interamericano.

De la caracterización de los derechos fundamentales como normas de jus cogens y de la obligación general de respeto a las mismas, se derivan varias consecuencias y efectos que se concretan en obligaciones específicas. La Corte determinará cuáles son esas obligaciones a través del objeto de la Opinión Consultiva: los derechos de los trabajadores migrantes indocumentados.

En el marco de una relación laboral en la cual el Estado se constituye en empleador, éste evidentemente debe garantizar y respetar los derechos humanos. La obligación impuesta al Estado no sólo opera cuando funciona como empleador, sino también cuando, actuando como legislador, regula las relaciones entre particulares y determina los contenidos de la legislación laboral. Sin embargo, las obligaciones del Estado van más allá, ya que en palabras de la Corte, el Estado será responsable cuando se cometa una violación de derechos fundamentales «respaldada por alguna directriz o política estatal que favorezca la creación o mantenimiento de situaciones de discriminación" en el ámbito laboral52. Así, la obligación de respeto prevista en el artículo 1.1 se concreta en tres vertientes respecto a los poderes públicos: primera, como una responsabilidad directa en su carácter de empleador; segunda, como obligación de adecuar su derecho interno a las disposiciones de la Convención y, tercera, como responsabilidad subsidiaria cuando, a través de sus políticas públicas, fomente acciones y prácticas de terceros que constituyan violaciones de derechos fundamentales ${ }^{33}$.

Ahora bien, en una relación laboral constituida por particulares, la CIDH establece que siendo el principio de igualdad —al igual que el resto de derechos de la $\mathrm{CADH}$ - una norma de jus cogens, acarrea obligaciones erga om-

51 Cfr. Opinión Consultiva 18/03, cit., fundamento 102 y ss. La cita de A. Gómez Robledo, proviene de su obra El Jus Cogens internacional. Estudio histórico crítico, Universidad Nacional Autónoma de México, México, 1982, pp. 20-21.

52 Cfr. Opinión Consultiva 18/03, cit., fundamentos 147, 152 y 170.

53 En el mismo sentido, véase el caso de la Masacre de Pueblo Bello contra Colombia, sentencia sobre el fondo de 31 de enero de 2006, fundamentos 126 y 151. Esta última vertiente, que no tiene precedente en la anterior jurisprudencia de la $\mathrm{CIDH}$ y que curiosamente tiene como origen varias resoluciones del Tribunal Supremo de los Estados Unidos en las que la intervención del Estado se interpreta como una forma de apoyo oficial que alienta o fomenta virtualmente la discriminación privada — véase por todas, Reitman v. Mulkey [387 U.S. 369 (1967)—-, es un claro reproche a la política estadounidense en materia de inmigración. Es importante recordar que en el caso Hoffman Plastic Compounds, origen de la solicitud de Opinión Consultiva, lo que de fondo se concluyó es que la política migratoria debe prevalecer sobre la política laboral. 
nes, lo que lo caracteriza como una norma de carácter necesariamente objetivo, y por tanto, que abarca a todos los posibles destinatarios, tanto a los integrantes de los órganos del poder público como a los particulares ${ }^{54}$. Para la Corte, los efectos de los derechos fundamentales frente a terceros están claramente configurados en el propio régimen jurídico de la Convención Americana, específicamente en el artículo 1.1 de la misma, que proclama el sometimiento tanto de poderes públicos como de particulares a la Convención.

La Opinión Consultiva 18/03, a juicio de la CIDH, se inscribe en "la doctrina jurídica denominada Drittwirkung, que se encuentra presente en buena parte de la jurisprudencia internacional ${ }^{55}$. Así, para la CIDH, la Opinión Consultiva 18/03 tiene una trascendencia respecto el sistema interamericano semejante a la que el caso Young, James and Webster $v$. The United Kingdom $(1981)^{56}$, o $X$ and $Y v$. Netherlands (1985) ${ }^{57}$, tienen en el marco de la Convención Europea de Derechos Humanos. En el último de estos casos, el Tribunal Europeo consideró que aún cuando el objeto del artículo 8 del Convenio (derecho al respeto de la vida familiar) es esencialmente la protección del individuo contra interferencias arbitrarias de autoridades públicas, existen obligaciones positivas inherentes al respeto efectivo de la vida privada y familiar, que pueden implicar "la adopción de medidas para asegurar el respeto a la vida privada inclusive en las relaciones entre particulares". Cierto sector de la doctrina ha querido ver en estas dos sentencias una buena muestra de que en el marco del Convenio Europeo la Drittwirkung es mediata, ya que el Tribunal Europeo no puede aplicar directamente una norma del Convenio para resolver un litigio entre particulares, sino, como mucho, condenar a algún Estado por no haber dispensado a sus ciudadanos una protección suficientemente efectiva frente a otros particulares ${ }^{58}$.

Creemos que esta apreciación no es del todo correcta, ya que, al igual que en el sistema interamericano, es cierto que sólo los Estados pueden ser condenados por la violación de los derechos del Convenio, y en este sentido sí podríamos hablar de una eficacia mediata; sin embargo, desde un punto de vista material, la eficacia es inmediata ya que lo que desencadena la responsabilidad del Estado es la previa lesión del derecho de un particular por otro particular ${ }^{59}$.

En cualquier caso, las consecuencias de la Opinión Consultiva 18/03 van más allá de la obligación del Estado de disponer de los medios necesarios

54 Cfr. Opinión Consultiva 18/03, cit., fundamento 140 y ss.

$55 \mathrm{Ibid}$, fundamento 140 y 143.

56 Sentencia del Tribunal Europeo de Derechos Humanos de 13 de agosto de 1981, serie A, núm. 44, párrafos 48 a 65 .

57 Sentencia del Tribunal Europeo de Derechos Humanos de 26 de marzo de 198, serie A, núm. 91, párrafo 23.

58 En este sentido, F. Rigaux, La protection de la vie privée et autres biens de la persounalité, Bruylant, Bruxelles, 1990, pp. 683-685.

59 En este sentido véase, J. M. Bilbao Ubillos, La eficacia de los derechos fundamentales frente a particulares, cit., p. 340 . 
para evitar o reparar las lesiones de derechos en las relaciones privadas. ${ }^{60} \mathrm{La}$ Corte Interamericana declara rotundamente y sin ningún género de dudas, como lo venía haciendo desde la segunda época de la jurisprudencia, que "los derechos fundamentales son límites directos al actuar de los particulares ${ }^{61}$.

Esta afirmación es reiterada en la jurisprudencia más reciente de la CIDH. Así, en los casos El Nacional, Asi es la Noticia y Globovisión contra Venezue$l a$, que versan sobre el acoso que durante los últimos años han sufrido los medios de comunicación independientes de Venezuela a manos de simpatizantes de la revolución bolivariana, la Corte no ha centrado su argumentación en la tolerancia y aquiescencia del régimen comandado por Hugo Chávez respecto a las actividades de estos grupos. Sus esfuerzos se dirigen a determinar que la libertad de expresión, como norma imperativa del sistema interamericana, es un límite directo que se impone en relación con actuaciones de terceros particulares, y en este sentido debe ser entendida y aplicada por los órganos judiciales de los Estados miembros ${ }^{62}$.

La doctrina consagrada en la Opinión Consultiva 18/03 ya ha sido acogida en la jurisprudencia más reciente de algunos tribunales latinoamericanos que se han caracterizado por negar a los derechos fundamentales cualquier tipo de multidireccionalidad, como es el caso de México. El asunto Alianza por Nayarit, resuelto por el Tribunal Electoral del Poder Judicial de la Federación en septiembre de 2005, es un claro ejemplo de ello ${ }^{63}$. El 3 de julio de 2005 se realizaron elecciones en el Estado mexicano de Nayarit para renovar, entre otros cargos, al Gobernador del Estado. Dicha elección arrojó la victoria del

60 Caso Myrna Mack Chang contra Guatemala, sentencia sobre el fondo de 25 de noviembre de 2003, fundamento 153; caso de los Hermanos Gómez Paquiyauri contra Perú, sentencia sobre el fondo de 8 de julio de 2004, fundamento 129; y caso del Instituto de Reeducación del Menor contra Paraguay, sentencia sobre el fondo de 2 septiembre de 2004.

61 Opinión Consultiva 18/03, cit., fundamento 151 y resultando quinto.

62 Caso Diarios El Nacional y Así es la Noticia contra Venezuela, resolución sobre medidas provisionales de 6 de julio de 2004, considerando 12; caso Emisora de Televisión Globovisión contra Venezuela, resolución sobre medidas provisionales de 4 de septiembre de 2004, considerando 11; caso Carlos Nieto contra Venezuela, resoluciones sobre medidas provisionales de 9 de julio de 2004, considerando 9; caso Carpio Nicolle contra Guatemala, resolución sobre medidas provisionales de 8 de julio de 2004; caso Gutiérrez Soler contra Colombia, resolución sobre medidas provisionales de 11 de marzo de 2005, fundamento 7; y caso de Los niños y adolescentes privados de libertad en el "Complexo do Tuatuapé" contra la República Federativa del Brasil, resolución sobre medidas provisionales de 30 de noviembre de 2005.

63 Sentencia de 14 de septiembre de 2005, emitida por la Sala Superior del Tribunal Electoral del Poder Judicial de la Federación. De conformidad con el artículo 99 de la Constitución mexicana, el Tribunal Electoral es la máxima autoridad jurisdiccional en la materia, con excepción de lo dispuesto en la fracción II del artículo 105 de la propia Constitución. Este precepto otorga atribuciones al Tribunal Electoral para resolver sobre las impugnaciones de las elecciones federales, estatales y municipales; la violación de los derechos político-electorales de los ciudadanos; la resolución de los conflictos laborales entre los servidores del Instituto Federal Electoral y sus trabajadores, así como las suscitadas entre los servidores con el propio tribunal. Asimismo, el precepto prevé que la Sala Superior realizará el cómputo final de la elección del Presidente de los Estados Unidos mexicanos, una vez resueltas las impugnaciones planteadas y formulará la declaración de validez de la elección y la de Presidente electo. 
Partido Revolucionario Institucional por un escaso margen de votos sobre una coalición electoral denominada Alianza por Nayarit. Dicha coalición promovió un juicio de inconformidad ante el Tribunal Electoral, en contra del cómputo y la declaración de validez de la elección. Entre sus agravios destaca el relativo a una supuesta falta de equidad en los medios de comunicación privados de la entidad, que, a juicio de Alianza por Nayarit, favorecieron descaradamente al PRI, en cuanto a tiempo en antena y contenidos.

Es importante mencionar que, en la primera fase del juicio de revisión constitucional electoral, la Sala del Tribunal Electoral del Estado de Nayarit determinó que los agravios de la coalición electoral resultaban infundados ya que los medios de comunicación "están en libertad de seleccionar a qué noticia o información le conceden un mayor tiempo o relevancia, en virtud de que los mismos desarrollan una actividad mercantil, que, como tal, tiene la finalidad de ofrecer al público un servicio permanente y más eficiente de comunicación, que les reporte un mayor beneficio de carácter económico" ${ }^{64}$. A juicio de la Sala Superior del Tribunal Electoral, la argumentación de la sala regional carecía de todo sustento, ya que "la existencia de un evidente, explícito y claro trato sistemáticamente inocuo o discriminatorio por los medios de comunicación privados hacia los partidos políticos, puede llegar a constituir violaciones a su obligación de respeto a los derechos de tercero" ${ }^{65}$.

Esta obligación de respeto de los derechos fundamentales por parte de los particulares, a juicio del Tribunal Electoral mexicano, abreva de dos fuentes. En primer término, de lo dispuesto por la CADH y la jurisprudencia de la Corte Interamericana, la cual "ha extendido el deber de respeto de los derechos sobre autoridades administrativas, legislativas y judiciales, así como otros sujetos normativos como las entidades de interés público, cualquiera que sea su naturaleza material u origen formal, como son los medios electrónicos de comunicación masiva ${ }^{66} ;$ y, en segundo lugar, de la supremacía normativa de las disposiciones constitucionales, la cual implica «un principio de vinculación, sujeción u obligatoriedad de primer orden para los depositarios del poder público del Estado y, en general, para toda persona individual o jurídica, ya sea oficial, social o privada" ${ }^{67}$.

La argumentación consagrada en el caso Alianza por Nayarit ha sido reiterada por el Tribunal Electoral en el caso Estado de México ${ }^{68}$, en el caso

64 Asimismo, la sala regional del Tribunal Electoral determinó que los medios de comunicación en México gozan de manera preferente de la garantía constitucional de libertad de expresión, que no se encuentra sujeta a limitación alguna que no sea el respeto a la vida privada, la moral y la paz pública, por lo que el contenido de las informaciones que publiquen los medios de comunicación social en el país son de su exclusiva responsabilidad, quienes tienen la plena libertad de elegir a qué nota o dato le otorgan mayor relevancia ( $C f r$. Sentencia 19 de agosto de 2005, emitida por la Segunda Sala del Tribunal Electoral del Estado de Nayarit)

65 Sentencia de 14 de septiembre de 2005, cit., p. 45.

$66 \mathrm{Ibid}, \mathrm{p} .55$.

67 Sentencia de 14 de septiembre de 2005, p. 54.

68 Sentencia de 14 de septiembre de 2005, emitida por la Sala Superior del Tribunal Electoral del Poder Judicial de la Federación, pp. 400-407 
Coabuila ${ }^{69}$, y en el Dictamen relativo al cómputo final de la elección de Presidente de los Estados Unidos Mexicanos, declaración de validez de la elección $y$ de presidente electo ${ }^{70}$.

Estas resoluciones son sólo una muestra de que el debate sobre la vigencia de los fundamentales en las relaciones privadas ha adquirido una complejidad mucho mayor en los sistemas jurídicos latinoamericanos a partir de la jurisprudencia de la $\mathrm{CIDH}$ en esta materia. Resulta impostergable que las cortes y tribunales constitucionales de los países latinoamericanos dejen a un lado el tradicional e injustificado recelo que la Corte Interamericana ha provocado en los ordenamientos internos desde su puesta en funcionamiento. Su jurisprudencia ha venido a dotar de nuevos contenidos y significados a los derechos fundamentales en Latinoamérica, por lo que desconocer y rechazar sus resoluciones no puede más que agudizar el déficit crónico de protección iusfundamental que sufren los habitantes del continente americano.

ABSTRACT. Through a study of the jurisprudence of the region over the last twenty years, it becomes possible to see that the CIDH has constructed an entire theory about the applicability of fundamental rights in relations between individuals in Latin America. Through this theory it has addressed the most important social problems in contemporary Latin American bistory, thus contributing to the transition to democracy for many countries in the region. The study will analyze the stages that the jurisprudence of the CIDH has

69 Sentencia de 23 de noviembre de 2005, emitida por la Sala Superior del Tribunal Electoral del Poder Judicial de la Federación, pp. 157-160.

70 Resolución de 5 de septiembre de 2006, emitida por la Sala Superior del Tribunal Electoral del Poder Judicial de la Federación, pp. 147-148. Es importante mencionar que tanto en Alianza por Nayarit, como en Estado de México y Coabuila, tres integrantes de la Sala Superior, los magistrados Fuentes Cerda, Luna Ramos y Navarro Hidalgo, emitieron un voto particular en contra de los razonamientos arriba expuestos. A su entender, "ni de la Convención Americana de Derechos Humanos ni de la Constitución mexicana (...) es posible extraer alguna disposición que permita afirmar que los individuos particulares están obligados a respetar los derechos fundamentales". Resulta patente que el voto particular omite consciente o inconscientemente, analizar ya no sólo de la reciente jurisprudencia de la Suprema Corte mexicana en esta materia, sino también la extensa y consolidada doctrina de la Drittwirkung que en los últimos años ha conformado la Corte Interamericana de Derechos Humanos. Únicamente se limitan a afirmar que lo establecido en los artículos 1 y 2 de la Convención Americana son mandatos dirigidos exclusivamente al Estado y que la multidireccionalidad de los derechos fundamentales sería contraria a los artículos 102 y 103 de la Constitución mexicana. El análisis en profundidad de esta cuestión puede ser consultado en J. Mijangos y González, Los derechos fundamentales en las relaciones entre particulares. Análisis del caso mexicano, cit., pp. 104-143. En cualquier caso, la argumentación vertida por los magistrados disidentes es un claro ejemplo de que en la mayoría de las ocasiones, los alegatos en contra de la multidireccionalidad de los derechos fundamentales, se limitan a evadir el problema sin apenas justificación. Me voy a permitir traer a colación el símil "futbolístico" propuesto por J. M. Bilbao Ubillos, en el sentido de que "los detractores de esta teoría se han limitado casi siempre a practicar un juego de contención, predoLa eficacia de los derechos fundamentales frente a particulares, cit., p. 851). 
passed through and which have led to the current criteria that this organization uses. The first stage consists of a series of rulings whose common denominator is the analysis of the obligation of respect and vigilance for fundamental rights by the states listed in article 1.1 of the American Convention on Human Rights. This principle, which is ever-present in its jurisprudence, brings the Inter-American Court to approaches that are similar to those proposed by the United States doctrine of state action, as it makes use of a good number of rulings made by the Supreme Court of the United States between 1960 and 1980. In the second stage, the importance originally placed on determining the characteristics of the agent who committed the violation of fundamental rights is replaced by a series of approaches in which the nature of the actual violation itself becomes the focus. In this phase, the Inter-American Court establishes the idea that the fundamental rights listed in the Convention are erga omnes obligations that are imposed not only in relation to the power of the State but also with respect to the actions of third-party individuals. Finally, the third stage in the evolution of the court's jurisprudence is represented by the most pertinent case in this matter: Opinion Consultiva 18/03, requested by the United Mexican States regarding the legal status of immigrants. This resolution, which has established a trend up until today, definitively establishes the direct effectiveness of the fundamental rights in relations between individuals. 